\title{
COMPARATIVE STUDY OF MACHINING TECHNOLOGY SELECTION TO MANUFACTURE LARGE-SIZE COMPONENTS OF OFFSHORE CONSTRUCTIONS
}

\author{
MariuszDeja ${ }^{1}$ \\ Mieczysław Siemiątkowski ${ }^{1}$ \\ Sender $\mathbf{P}^{2}$ \\ ${ }^{1}$ Gdansk University of Technology, Mechanical Engineering Faculty, Dept. of Manufacturing Eng. \\ and Automation, Gdansk, Poland \\ ${ }^{2}$ Elektromontaż-Północ Gdynia S.A. (EPG), Poland
}

\begin{abstract}
The focus of this paper is on process planning for large parts manufacture in systems of definite process capabilities, involving the use of multi-axis machining centres. The analysis of machining heavy mechanical components used in off-shore constructions has been carried out. Setup concepts applied and operation sequences determined in related process plans underwent studies. The paper presents in particular a reasoning approach to setup sequencing and machine assignment in manufacturing large-size components of offshore constructions. The relevant reasoning mechanism within a decision making scheme on generated process plan is shown based on a case study derived from the offshore sector. Recommendations for manufacture of selected exemplary and typical parts were formulated.
\end{abstract}

Keywords: off-shore construction, heavy mechanical component, multi-axis machining centre, process planning

\section{INTRODUCTION}

Large-size and heavy mechanical components have numerous applications in up-to-date industry. Consequently, there is an increased demand on them, especially in regards to fast-growing sectors, among others: renewable energy power stations (e.g. wind turbines), maritime industry, including offshore platforms as well as shipping equipment. Components of such kind are often machined by specially developed machine tools: workshop or portable machines for in-situ manufacture and inspection $[9,11,13,16]$. Significant aspects related to manufacturing and possibly maintenance and repairing of large-size and accurate parts are indicated in Fig.1. Related equipment of large-size machines involving laser trackers and rotary tables help in part handling while locating and centring the part in order to minimise the number of setups and shortening the overall machining time - Fig. $1 \mathrm{~b}$. The specific shape and weight of big components, especially those of prismatic configuration with protruding features, require special considerations on design of supporting elements needed for safety reasons and to avoid possible deformation of the part on the machine tool - Fig. 1 c. Portable machines are used due to their mobility in those branches of the industry where the size of components and their availability is considered to be a problem in the production technology, the assembly area and repair $[6,17]$. They form an alternative to stationary machining devices and eliminate the need for their disassembly and transportation Fig. 1d. Regeneration works performed on maritime internal 
combustion engines, water power plants or steam turbines may also require a narrow technical specialisation of the staff operating the mobile machines to eliminate or reduce the costs of transport and preparation of a repair service of large-parts. The continuity of the production process can be restored much quicker than after parts reassembling. As reported in [12], turbine housings of more than 9000 $\mathrm{mm}$ in diameter can be machined with the use of a mobile system based on a mobile parallel kinematic machine tools for 5-axis machining and equipped with a highly accurate angle measuring system inside the rotary table and tactile measuring of reference geometries on the work part.

Constructions associated with application of large-size machine tools have not been searched sufficiently by research institution. The reason for that might be the relatively high cost involved in necessary experimentation. There are also relatively few reports derived from industrial area as well. Selected issues of full scale parts manufacture are discussed in following chapters of the paper work with illustrative case production plant operating in an offshore engineering area.

\section{PROCESS REQUIREMENTS VERSUS MACHINE CAPABILITY OF LARGE- SIZE COMPONENTS IN OFFSHORE CONSTRUCTIONS}

Kinematical possibilities of modern CNC centres with driven tools allow for processing machining features characteristic for both: prismatic and rotational parts. study derived from industrial practice of a middle-sized

Components with prismatic and rotational features are defined as prisronal parts in[18]. The main tendency in the design of large- size machine tools is to ensure possibility of machining axial-symmetric parts on CNC milling centres and prismatic parts on $\mathrm{CNC}$ lathe with a controlled rotation of a rotary table for obtaining required geometry and tight tolerances $[5,13]$. Technological problems which can be easily solved on conventional size machine tools represent a huge challenge for big and accurate dimensions, mostly within a tolerance grade of IT7, and obtained on large-size machine tools. Cylindrical shapes, like in cylindrical bars, can be made by turning with fixed cutting tools or with driven tools. Conventional turning is possible if the machined diameter and available rotations (sometimes limited to $2 \div 5 \mathrm{rpm}$ or even lower for non-symmetric parts) ensure obtaining the required cutting speed.

The main kinematics configurations of milling machines for large parts are with movable column (Fig. 2 a) or gantry type. Controlling 5 axes of the machine is possible by the installation of automatic swivelling head on a multi-tasking milling machine tool $[7,9]$. The machining features of a part clamped in a fixed position are easily accessible by the tools mounted in a spindle of movable column machines. A vertical lathe is dedicated to large rotational parts for turning the diameters ranging from $1.5 \mathrm{~m}$ to more than $6 \mathrm{~m}$ with the possibility of complete machining, by conducting milling, drilling, boring and even gear cutting in a single set-up using additional spindles and equipment, e.g. a swivelling head Fig. 2 b, changed manually or automatically.

Static deformation of large parts due to their own weight must be considered in detail while choosing fixtures to locate, clamp and support a workpiece during machining. Fixtures

b)

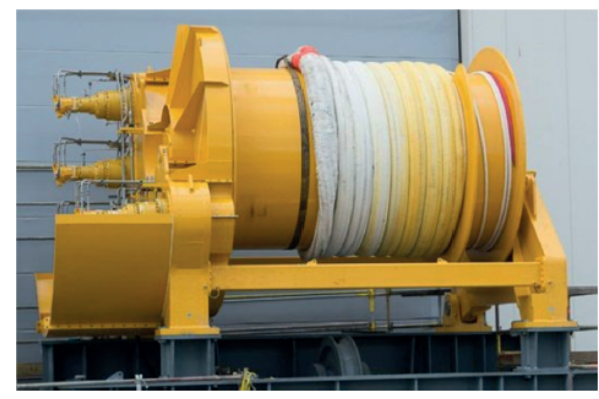

c)

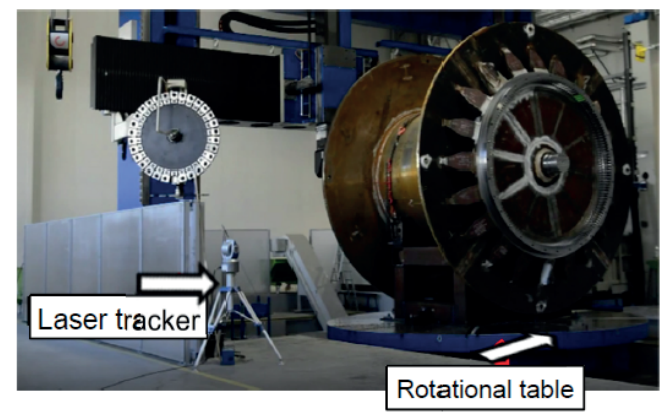

d)
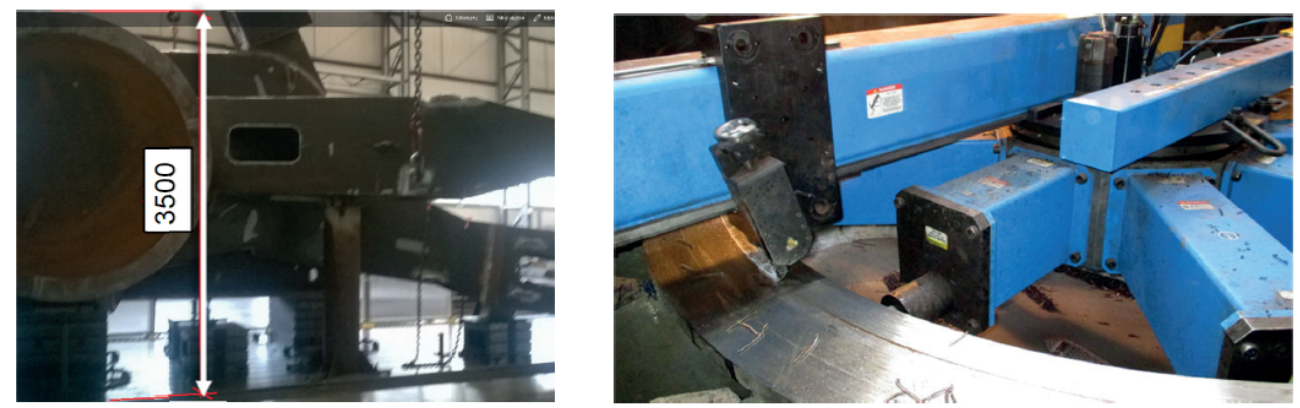

Fig. 1. Manufacturing aspects of large-size parts for offshore structures: a) a winch dedicated to shipping and offshore industry [21], b) a winch drum with 800 tons pulling force mounted for machining on a machine tool in EPG (Energomontaż-Pótnoc Gdynia S.A. plant, c) supporting a large part on a machine tool in EPG plant, d) a mobile precise lathe for flanges of diameter $1143 \div 6000 \mathrm{~mm}$ [22] 
should be designed so that the workpiece is not deformed under its own weight due to plastic deformation. Finite element analysis was carried out with the use of Autodesk Inventor ${ }^{\circledast}$ software for a sample component made of highstrength low-alloy steel (Young's modulus $\mathrm{E}=200 \mathrm{GPa}$, Poisson's ratio $v=0.29$ ) to predict its deformation (Fig. $3 \mathrm{~b}$ ). The related deformation can be significantly minimised by additional technological fixturing features (Fig. $3 \mathrm{c}, \mathrm{d}$ ), intelligent fixtures, CNC part program compensation $[2,8$, $10]$ and relying on the experience of the operator [17].

a)

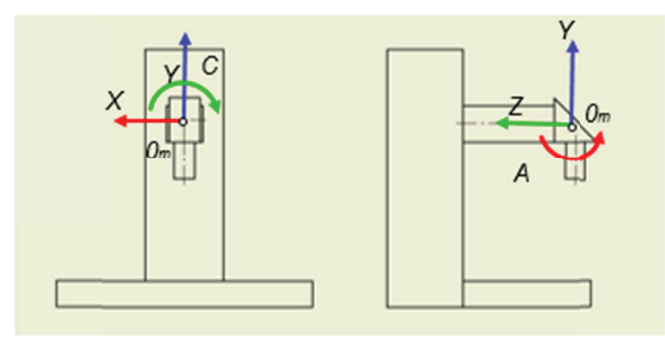

b)
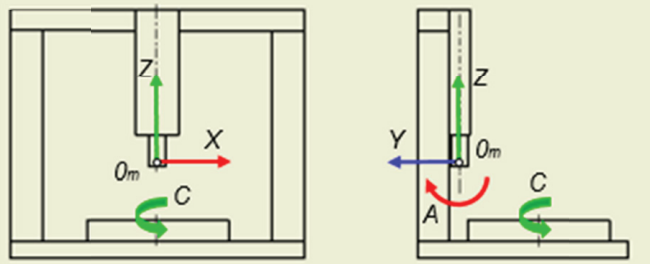

Fig. 2. Configurations of large workshop machines: a) 5-axis CNC horizontal milling centre, b) 5-axis CNC vertical turning centre (a multi-tasking vertical lathe); all systems equipped with a 2-axis swiveling head

a)

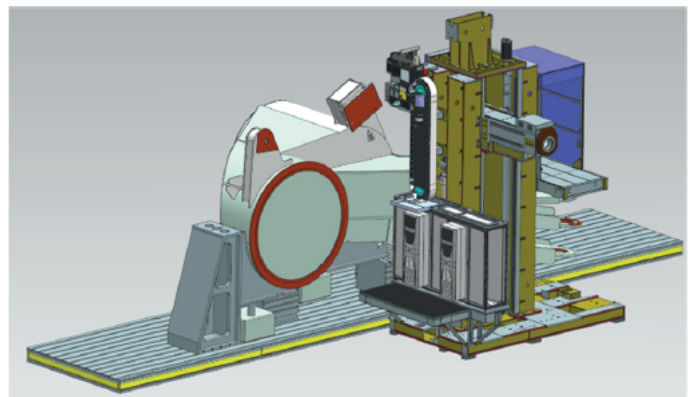

c)

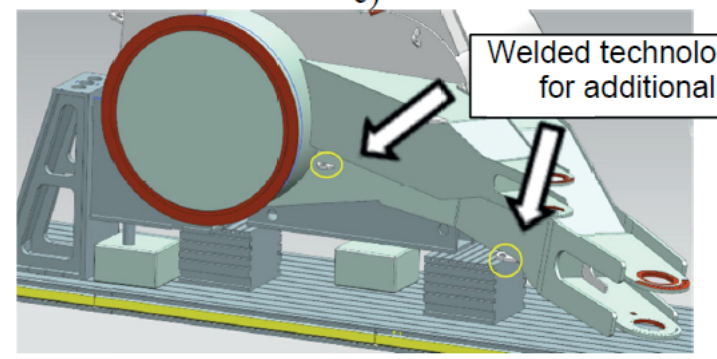

Fig. 3. Placement and orientation of a prismatic part on the horizontal milling centre (a), along with the FEA analysis of a part deformation for a chosen support (b) and with welded technological fixturing features for additional clamping $(c, d)$

\section{MANUFACTURING PROCESS PLANNING FRAMEWORK FOR FULL-SCALE PART COMPONENTS}

Fabrication of part machining features in proper setups and sequence is particularly significant as far as the manufacture of large- size and heavy components is concerned. This is because of extremely long times involved in such preparatory operations as laying out and checking the material allowance available, performed within intermediate storage sites, and preceding also time consuming part positioning in working space of a definite machine tool. As a result, process planning involving the selection of adequate processing technologies under consideration of available machine capabilities is the matter of great importance in here.

\section{INTEGRATED GENERIC REASONING SCHEME FOR SETUP PLANNING AND MACHINE ASSIGNMENT}

In this research, the task of machining process sequencing alternatives for parts types under consideration encompasses sequencing features provided in the form of a list. Within this context, the related task can be accomplished by grouping features of the attributed list into setups first, along with their assignment to machines available in a facility, and then possible sequencing the features in each setup based on definite reasoning technological rules. The former stage of the two-stage decision framework as orientated to fullscale parts manufacture is discussed most extensively in this research. The proposed decision making scheme for generation of process alternatives assumes input data model including the description of both features themselves and also concerning precedence relationships for the features,

b)

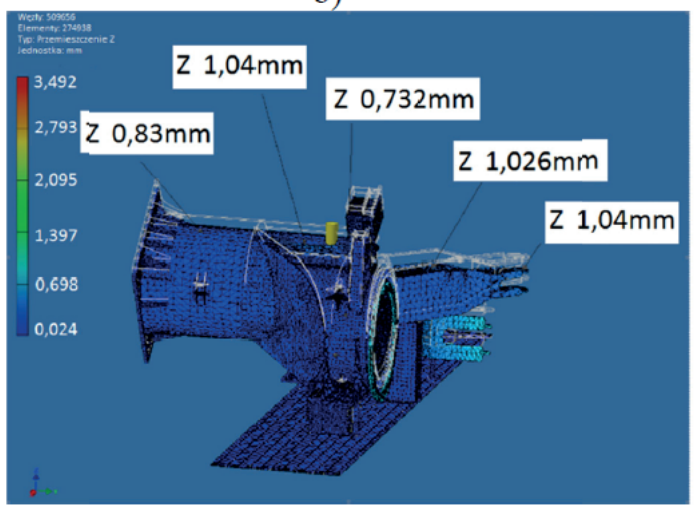

d)

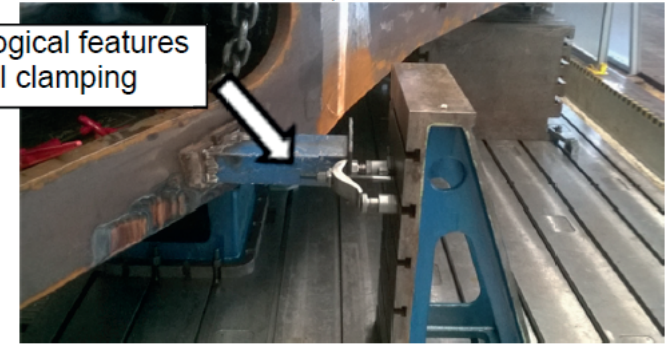


while considering constraints related to setup planning in parts manufacture. Therein, it seems to be reasonable to apply specific heuristics to process sequencing that are valid in the area of large-size parts manufacture and often observed in industrial practice. The decision making process entails the need for further consideration on datum reference selection and part placement on individual machines that is assigned to the stage of feature grouping for consecutive setups created that is discussed closer underneath.

\section{OPERATION SEQUENCING STRATEGY FOR LARGE- SIZE PARTS MANUFACTURE}

The approach applied to solving process sequencing problem utilises heuristic premises coming from accumulated technological knowledge and reported industrial experience. Each of machining technologies like milling, drilling, turning or grinding might have its own specified tool approaching direction (TAD) [19] which can be assigned to each feature $[3,20]$ for automatic process planning realised with computer support. If features have more than one TAD, definite TAD should be assign to every feature according to some priorities of tight tolerance relation between features, the number of features and good machining practices [20]. Providing more TADs by a machine tool can reduce the number of setups [3]. To avoid relocation of large parts, features in one TAD should be machined in a single setup although features machined in one setup are not necessary in one TAD [20]. Most parts have surfaces to be machined parallel to the natural axes and planes of the workpiece linear coordinate system but positioning of large parts on the machine could be a very long process taking even a few days.

As noted, most of the research works on machining feature sequencing focused either on prismatic or rotational parts. For effective setup planning, machining features need to be properly oriented with regard to the spindle axis of the machine tool $[1,3,4]$ which is typically a $Z$-axis. Prismatic features made on four- or five-axis lathes must be oriented with regard to the spindle axis of the driven milling-drilling tools.

The demanded orientation of features is defined by the feature working direction which is the same as $T A D$ vector along the spindle axis of the machine tool for turning features made on lathes or prismatic features made on milling machines. Prismatic features made on turn-mill centres are oriented along the spindle axis of a driven tool. Like in [1] the feature working direction is described by the direction cosines of a main $T A D$ vector along a spindle axis with respect to an assigned workpiece linear coordinate system.

General description of the working direction of a feature $F_{i}$, which should be considered together with the feature type, is given by an ordered triple:

$\boldsymbol{W D}_{i}=\left[\cos \left\{\boldsymbol{T A} \boldsymbol{D}_{i}, x_{w p}\right\}, \cos \left\{\boldsymbol{T A} \boldsymbol{D}_{i}, y_{w p}\right\}, \cos \left\{\boldsymbol{T A} \boldsymbol{D}_{i}, z_{w p}\right\}\right]$

(1) where:

$\cos \left\{\boldsymbol{T A} \boldsymbol{D}_{i}, x_{w p}\right\}, \cos \left\{\boldsymbol{T A} \boldsymbol{D}_{i}, y_{w p}\right\}, \cos \left\{\boldsymbol{T A} \boldsymbol{D}_{i}, z_{w p}\right\}-$ cosines of the angles between the TAD of the feature Fi and three workpiece coordinate axes.

As a consequence, the implied approach to setup planning and operation sequencing is based on unified model involving the specifications of feature working directions with respect to an assigned work part linear coordinate system as well as the direction cosines used to describe its orientation with regard to the machine linear coordinate system. Assigning features to appropriate setups proceeds after the determination of a primary locating direction and selection of datum reference feature. The decision making procedure involves considerations on configuration and kinematics characteristics of machines available in the definite machining facility, as outlined in Fig.6.

\section{AN INDUSTRIAL CASE STUDY OF PART MANUFACTURE FOR OFFSHORE APPLICATIONS}

In order to illustrate the developed reasoning framework with broader reference to diverse aspects of large-size parts manufacture, an industrial case study derived from EPG S.A. - a production plant located in Gdynia (Poland) is presented. It is intended primary to show the machining process alternatives together with adequate part fixturing strategies on available CNC multi-axis machine tools of different configuration and processing capabilities.

The drum of a winch shown in Fig. 1 b, has been selected as the exemplary large-size component applied to diverse offshore constructions for testing the proposed decision making scheme. Sets of representative machining features for the component, that principally falls into the category of mill-turn parts, were determined on the basis of technological knowledge and practical applications - Fig. 4 and Table 1. Most of the features with TAD lying along the axis of a part rotation has the same $\cos \left\{T A D_{i}, x_{w p}\right\}, \cos \left\{T A D_{i}, y_{w p}\right\}-$ Fig 4 . The difference in $\cos \left\{T A D, z_{w p}\right\}$ indicates working direction change and the need for a new subset or changing the part position around $180^{\circ}$. One of the features distinguished (side hole) has the working direction $[0,-1,0]$ that is perpendicular to the main datum axis of the analyzed mill-turn work part.

Possible orientations of an exemplary part, with the overwhelming number of rotational surfaces, on typical and available machine tools are presented in Fig. 5. In chosen machine configurations there is a problem with the accessibility of features from both working directions $[0,0,-1]$ and $[0,0,1]$ in a single setup, therefore two setups are necessary for complete machining. This, in turn, gives rise to additional difficulties in the reorientation of large and heavy parts and its proper positioning for continued machining. Moreover, the diameter of an outer cylindrical surface is too small for obtaining required cutting speed. Part orientation on a vertical turning machine equipped with rotary table, shown in Fig. 1 b, allows for changing the part position around $180^{\circ}$, although the symmetry axis of a 


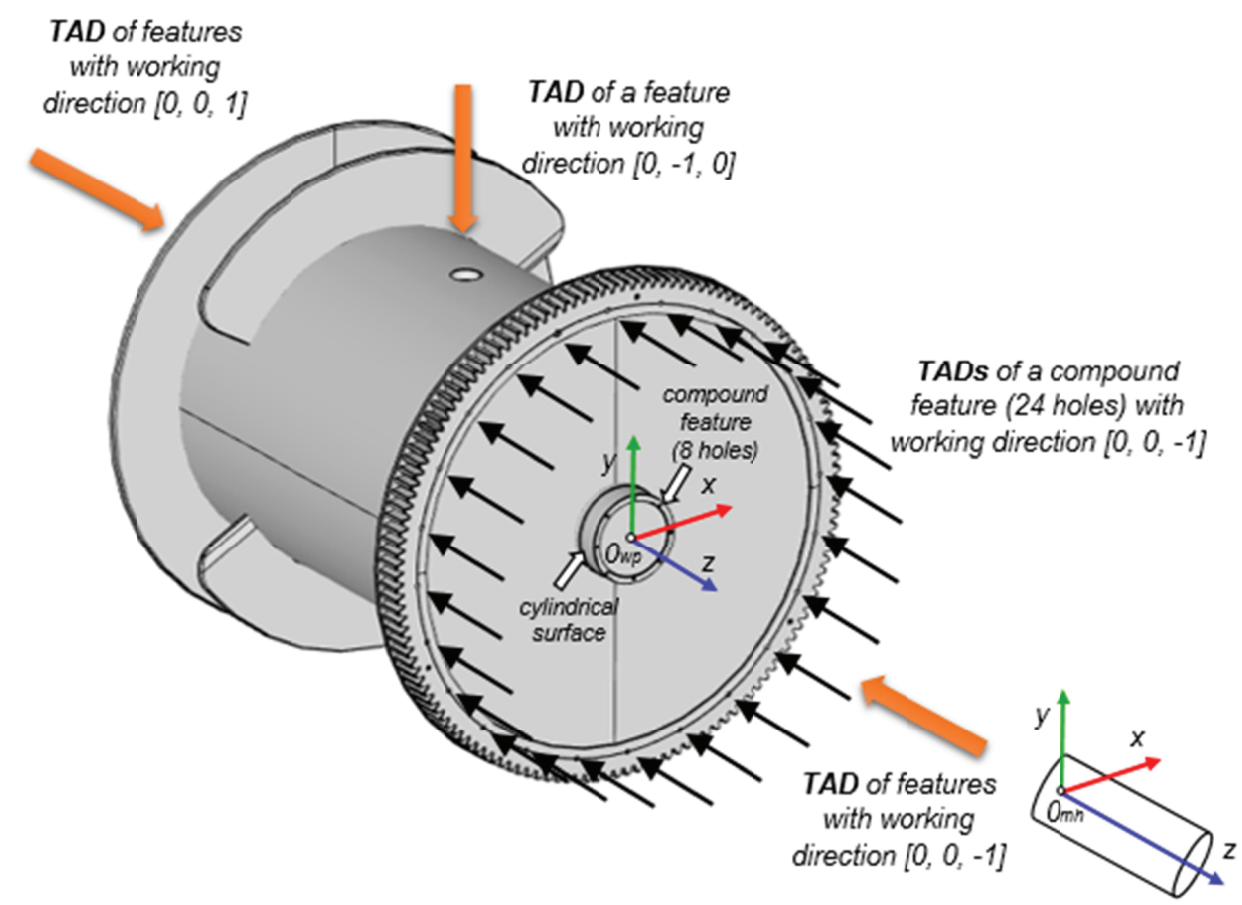

Fig. 4. Standard placement of a sample part (3787 $\mathrm{mm}$ in length and outer diameter of $3340 \mathrm{~mm}$ ) in working space of the horizontal type machine and definition of working directions of machining features with respect to workpiece coordinate system

part is located horizontally and perpendicularly to the axis of a rotary table. It might be noted that machining of outer cylindrical surface - Tab. 1, is enabled owing to the available equipment for turning or milling solely in the horizontal part orientation on a vertical lathe or a horizontal milling machine.

a)

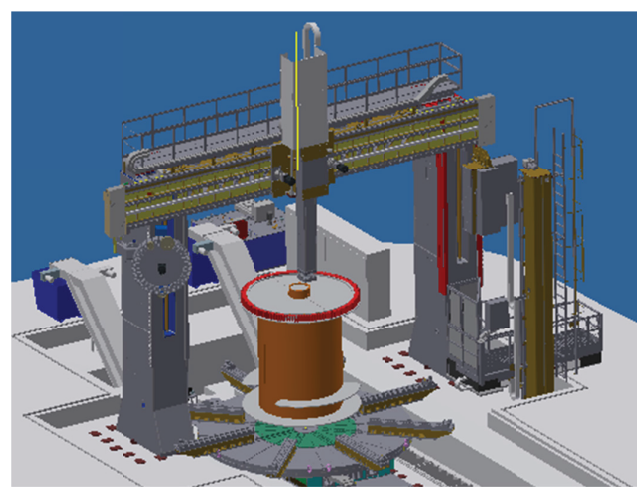

b)

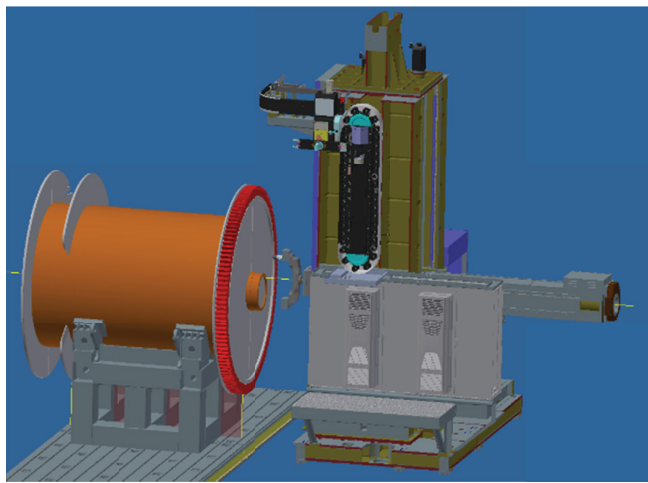

Fig. 5. Possible placement and orientation of the exemplary part type on a rotary table of a vertical lathe using independent chucks for centering (a) and a horizontal milling machine using V-block locating (b)
Alternative process capabilities have been considered in this research assuming an extended set of machine resources and related equipment. Three machine alternatives, however, are included into further comparative analysis, and with reference to the specified machining features of a winch drum as the exemplary part design, and envisaged as those performed within a primary part setup (Table 1). Following the suggestions reported in $[14,15]$, the operation alternatives are depicted in this Table by definite schemata, associated with machining the specified set of features of the primary part setup. Thus, in accordance with the reports mentioned, an individual schema is due to be understood as a technologically meaningful combination of a tool type (accordingly to a machining method) and a set of relative motions between a work part (WP) and the tool (T) of a specific geometry. Each of the schemata defined involves the designation of operation kinematics with the primary motion expressed by the cutting speed $-v_{c}$, and the feed speed $-v_{f}$ attributed to a definite system component, a.e. a work part or the tool applied, respectively. With reference to the working step of face milling for instance: the cutting speed $v_{c}=240 \mathrm{~m} / \mathrm{min}$, the feed per tooth $f_{z}=0.3 \mathrm{~mm}$ and working engagement $a_{e}$ - equal to $75 \%$ of the head diameter were applied for machining using the working head equipped with octagon milling inserts. Such a tool type is extensively used in manufacturing offshore components while the removal of high volumes of excess stock material and high process productivity are demanded. The aforementioned rules are generally valid as far as the consecutive part setups are concerned, and throughout the decision steps of the developed reasoning algorithm, summarised in Fig. 6. 


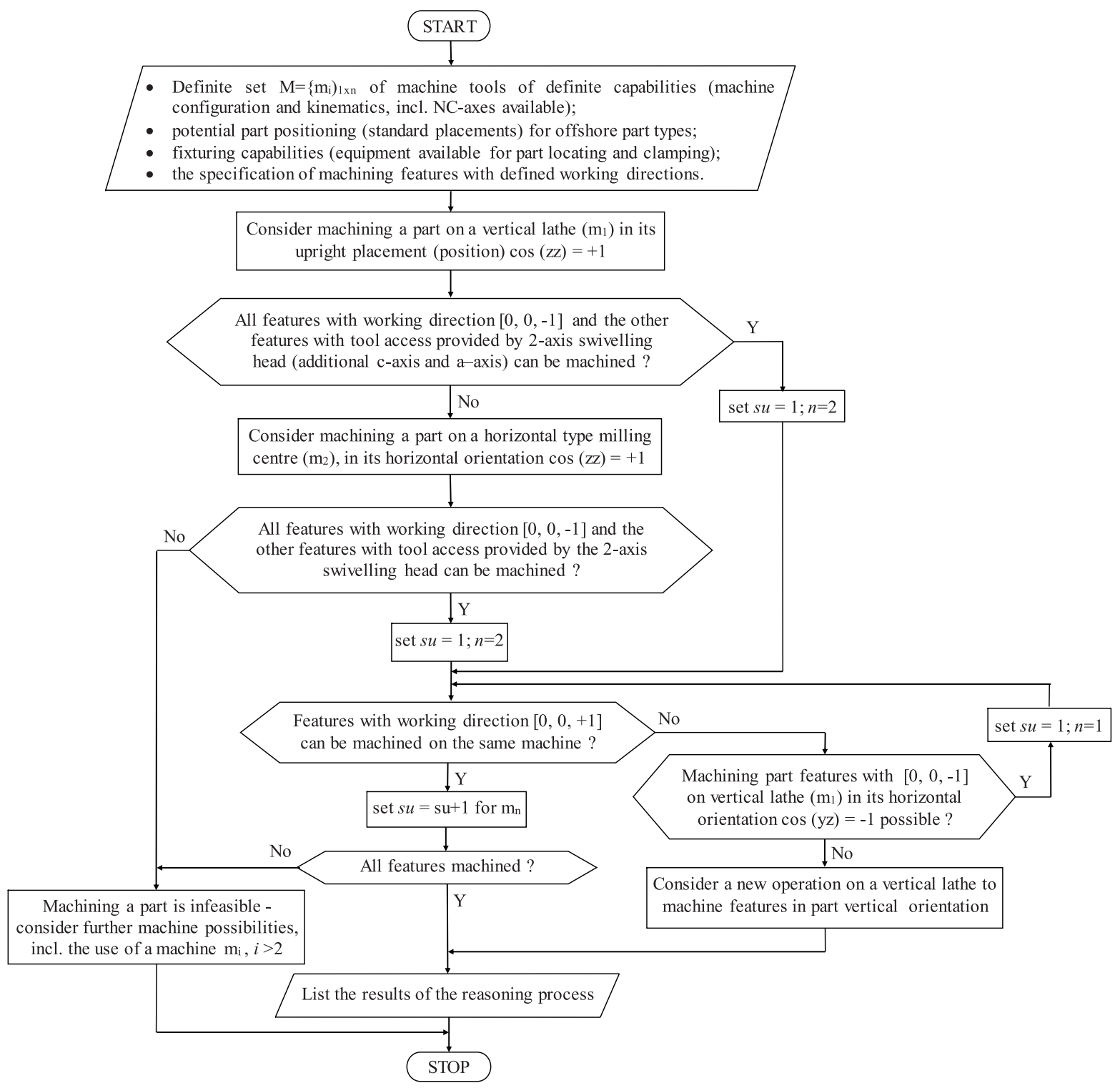

Fig. 6. Reasoning approach to setup sequencing and machine assignment in manufacturing large-size components of offshore constructions ( a simplified outline)

\section{BIBLIOGRAPHY}

1. Celano G., Costa A., Fichera S. and Santangelo B.: Pallet configuration for approaching mapping requirements on devices, Chapters 6 in: Design of flexible production systems: methodologies and tools, Tolio T (Ed.), Springer -Verlag 2009.

2. Choi J.P., Min B.K. and Lee S.J.: Reduction of machining errors of a three-axis machine tool by on-machine measurement and error compensation system. Journal of Materials Processing Technology, Vol. 155-156 (2004), pp. 2056-2064.

3. Deja M. and Siemiatkowski, M.S.: Feature-based generation of machining process plans for optimised parts manufacture. Journal of Intelligent Manufacturing, Vol. 24 (2013), pp. 831-846.
4. Gologlu, C.: Machine capability and fixturing constraintsimposed automatic machining set-ups generation, Journal of Materials Processing Technology, Vol. 148 (2004), pp. 83-92.

5. Groover M.P.: Fundamentals of modern manufacturing, Materials, processes and systems, J. Wiley \& Sons Inc., 2010.

6. Haddag B., Nouari M. and Moufki A.: Some cases of machining large-scale parts: characterization and modelling of heavy turning, deep drilling and broaching, AIP Conference Proc. 1716, AIP Publishing 2016, pp. 1-9.

7. Jang S.H, Choi Y.H., Kim S.T., An H.S., Choi H.B. and Hong J.S.: Development of core technologies of multi-tasking machine tools for machining highly precision large parts. Journal of the Korean Soc. for Precision Engineering, Vol. 29, No.2 (2012), pp. 129-138.

8. Kaliński K.J. and Galewski M.: Chatter vibration 
surveillance by the optimal-linear spindle speed control. Mechanical Systems and Signal processing, Vol. 25 (2011), pp. 383-399.

9. Lizarralde R., Azkarate A. and Zelaieta O.: New developments in lathes and turning centres, Chapter 7 in: Machine tools for high performance machining, Lopez de Lacalle L.N and Lamikiz A. (Eds), Springer-Verlag 2009.

10. Mares M., Horejs O. and Hornych J.: Advanced thermal error compensation of a flor type machining centre allowing for the influence of interchangeable spindle heads, Journal of Machine Engineering, Vol. 15, No. 3 (2015), pp. 19-32.

11. Matuszewski A. Musiał J. and Styp-Rekowski M.: Design and technological issues related to large parts of the modular structure (in Polish), Technologia i Automatyzacja Monażu, No. 2 (2012), pp. 28-30.

12. Neugebauer R., Wabner M., Rentzsch H. and Ihlenfeldt S.: Structure principles of energy efficient machine tools. CIRP Journal of Manufacturing Science and Technology, Vol. 4 (2011), pp. 136-147.

13. Onozuka H., Utsumi K., Kato T., Takahashi H. and Obikawa T.: Optimal design of a damped arbor for heavy duty machining of giant parts. Journal of Advanced Mechanical Design, Systems, and Manufacturing, Vol. 7, No. 2 (2013), pp. 171-186.

14. Ratchev T.M.: Concurrent process and facility prototyping for formation of virtual manufacturing cells. Integrated Manufacturing Systems, Vol. 12, No.4 (2010), pp. 306-315.

15. Siemiątkowski M. and Przybylski W.: Modelling and simulation analysis of process alternatives in the cellular manufacturing of axially symmetric parts. Intl. Journal of Advanced Manufacturing Technology, Vol. 32, Nos.5-6 (2007), pp. 516-530.

16. Simpson B. and Dicken P.J.: Integration of machining and inspection in aerospace manufacturing, IOP Conf. Series: Materials Science and Engineering, Vol. 26 (2011), pp. 1-4.

17. Uriarte L., Zatarain M., Axinte D., Yague-Fabra J., Ihlenfeldt S., Eguia J. and Olarra A.: Machine tools for large parts. CIRP Annals-Manufacturing Technology, Vol. 62 (2013), pp. 731-750.

18. Waiyagan K. and Bohez E.L.J.: Intelligent feature based process planning for five-axis multi-turn parts. Computers in Industry, Vol. 60 (2009), pp. 296-316.

19. Yao S., Han X., Yang Y., Rong Y., Huang S., Yen D. and Zhang G.: Computer aided manufacturing planning for mass customization: part 2, automated setup planning. Intl. Journal of Advanced Manufacturing Technology, Vol. 32
(2007), pp. 205-217.

20. Zhang, H-C. and Lin, E.: A hybrid-graph approach foe automated setup planning in CAPP. Robotics and ComputerIntegrated Manufacturing, Vol. 15 (1999), pp. 89-100.

21. http://www.gospodarkamorska.pl/wydarzenia/wciagarkaz-energomontazu-polnoc-gdynia-dla-norweskiegoprzemyslu-offshore.html, accessed on February $16^{\text {th }} 2017$.

22. http://en.nglmachining.com/park-maszynowy.html, accessed on February 16th 2017.

\section{CONTACT WITH THE AUTHOR}

Mariusz Deja

Gdańsk University of Technology

11/12 Narutowicza St. 80 - 233 Gdańsk

Poland 